\title{
A Community Level Sample Survey to Determine CurrentUnderstanding About Medical Recycling of Cardiovascular ImplantableElectronic Devices
}

\author{
Milan Mahesha, Munish Sharma ${ }^{\mathrm{b}}$, Daniel AN Mascarenhas ${ }^{\mathrm{c}, \mathrm{d}, \mathrm{e}}$
}

\begin{abstract}
Background: Medical recycling and reutilization of cardiovascular implantableelectronic devices (CIEDs) have a significant impact not only in patientsof low-income countries but may also in certain patients in the UnitedStates who do not have sufficient medical insurance coverage. Themain determining factor for future utility and popularity of recycledmedical devices is thorough understanding about this topic amongstpublic and healthcare professional. To the best of our knowledge,there has been no study conducted so far at a community level to determinethe understanding in public and healthcare personnel about recyclingof medical devices including CIEDs. We sought to determine existingknowledge and attitude about recycling of CIEDs amongst representativesample population in a community.
\end{abstract}

Methods: A questionnaire was sent for online completion to multiple peoplein the community, healthcare and funeral home in Lehigh Valley, Pennsylvania,USA. The questionnaire was designed in order to assess three maincategories; knowledge, attitude and practice. We called this a KAPstudy which is an acronym for knowledge, attitude and practice survey.

Results: We got 117 responses to our questionnaire from community members(55.45\%), 89 responses (42.18\%) from the healthcare personnel andfive responses (2.37\%) from funeral homes. About $30.77 \%$ communityparticipants had heard about medical devices recycling compared to $57.30 \%$ participants from healthcare sector. A total of $88.64 \%$ of medicalprofessionals were aware that there are people in the world who diebecause they cannot afford CIEDs while $73.50 \%$ of community participantswere also found to be aware of this fact. Higher percentages of healthcareprofessionals were found to be willing to personally consider a decisionabout medical device donation compared to community participants.

Manuscript submitted July 10, 2018, accepted July 20, 2018

${ }^{a}$ Moravian Academy, Bethlehem, PA, USA

bepartment of Heart Failure and PulmonaryHypertension, Hackensack University Medical Center, Hackensack, NJ,USA

${ }^{\mathrm{c}}$ Drexel University College of Medicine,Philadelphia, PA 19129, USA

dEaston Hospital, Easton, PA 18042, USA

${ }^{e}$ Corresponding Author: Daniel ANMascarenhas, Drexel University College

of Medicine, Philadelphia,PA 19129, USA. Email: danmasc@rcn.com

doi: https://doi.org/10.14740/cr755w
Conclusions: CIED reutilization can improve quality of life among many patientswith low or medium socioeconomic status. People should be made moreaware about the benefits of CIED reutilization. Concerns about device-relatedinfections, complications and law suits should be addressed to helpimprove their utility.

Keywords: Medical device recycling; Cardiovascular electronic implantable devices; Sample survey; Quality of life

\section{Introduction}

With technological advancement in healthcare industry, there isan increasing need of systematic disposal of old medical devices.In cases of medical devices that can be sanitized and verified forsignificant functionality, the concept of reuse for the benefit oflow- and medium-income communities, who are neither able to affordmedical insurance nor able to buy such devices, can be of tremendoushelp. This concept of medical recycling has been found to be promisingin cases of cardiovascular implantable electronic devices (CIEDs)explanted from a deceased person as evident in multiple studies publishedpreviously [1-3]. Permanent pacemakers (PPM) andimplantable cardioverter defibrillators (ICD) are primarily referredto as CIEDs. Their recycling and reutilization can make a significantimpact in terms of health-related quality of life and longevity ofthe patients suffering from cardiovascular diseases $[1,4]$. An ICD generator may cost between 20,000 US dollar (USD)and 40,000 USD while a PPM can cost 2,500 to 3,000 USD on an average[1]. The average costs of CIEDsexceed the per capita annual income of most of the people living inlowand middle-income countries [5]. Thus, medical recycling and reutilization of CIEDs canhave a significant impact not only in patients of low-income countriesbut also in certain patients in the United States (USA) who do nothave sufficient medical insurance coverage. This can also decreasecost of healthcare in the USA that is spiraling out of control. Accordingto a study published in 2015, the total health care cost of patientsundergoing revision of CIED itself was approximately 185 million USDbetween 2004 and 2014 [6].The main determining factor for future utility and popularity of recycledmedical devices is thorough understanding about this topic amongstgeneral public and healthcare professional. To the best of our 


\section{Table 1. Questionnaire Used for Survey}

1 Before beginning this survey, have youheard the term "medical device recycling" and/or "medicaldevices recycling?"

2 Do you have any medical devices implantedin you like pacemaker or implantable cardioverter defibrillator?

3 Do you know any family members or friendsthat have medical devices implanted in them like pacemakers or defibrillators?

4 On review of is that these devices couldpotentially be removed after death and donated to other people?

5 Before this questionnaire, were youaware that there are people in the world who die of heart diseasesbecause they cannot afford pacemakers or defibrillators?

6 On a scale of $1-5$, how likely areyou to personally consider/influence a decision about medical donation?

7 Do you think participation in medicaldevice donation adds meaning to one's life?

8 Do your beliefs (religious or otherwise)potentially disallow U from participating in device donation?

9 In your mind, what is the most importantconcern about medical device donation?

10 What do you think mostly happens tothese medical devices?

11 Roughly what percentages of it do youthink are trashed?

12 Roughly what percentages do think thatgiven to other people in need?

13 If there was a mechanism where medicaldevices and/or devices could be donated legally to poor and needypeople overseas, would you be willing to spread the word and/or participatein the same?

14 If there was a mechanism where medicaldevices and/or devices could be donated to needy people locally inthe community, would you be willing to spread the word and/or participatein the same?

15 Do you think participation in devicedonation adds meaning to your organization's core mission?

16 Would the hospital or healthcare organizationyou associate with be willing to potentially implement a program ofpost-mortem CIED donation?

17 Would the hospital or healthcare organizationyou associate with be willing to potentially implement a program ofpost-mortem CIED donation?

18 Would your organization's beliefsand values potentially disallow you from participating in device donation?

19 We would welcome your additional inputon the topic. Questions? Ideas? Thoughts? Concerns?

knowledge, there has been no study conducted so far at a community level to determinethe understanding in general public and healthcare personnel aboutrecycling of medical devices including CIEDs. In this study, we soughtto determine existing knowledge and attitude about recycling of CIEDsamongst representative sample population in a community. We also aimedto determine factors affecting current attitude towards this approachand main concerns about reutilization of CIEDs.

\section{Materials and Methods}

A questionnaire was sent for online completion to multiple peoplein the community, healthcare and funeral home in Lehigh Valley, Pennsylvania,USA. The questionnaire was designed in order to assess three maincategories; knowledge, attitude and practice. We called this a KAPstudy which is an acronym for knowledge, attitude and practice survey.This survey intended to assess baseline knowledge, measure attitudeand recognize any barriers to practice. Questionnaire had common setof questions as well as those modified to suit the nature of the respondergiven the fact that the participants were both healthcare professionalsand community members. Categorical data obtained in the study havebeen presented as frequencies and/ or percentages. Where ever applicable,P-value was calculated by $t$-test and a $\mathrm{P}$ value of $<0.05$ was considered statistically significant.

\section{Questionnaire used for survey}

Table 1 shows the questionnaireused for survey.

\section{Results}

There were totally 211 respondents in the survey. All the participantsin the survey were more than 18 years in age. We got 117 responsesto our questionnaire from community members $(55.45 \%), 89$ responses $(42.18 \%)$ from the healthcare personnel and five responses $(2.37 \%)$ from funeral homes. Amongst the healthcare professionals, $59(66.29 \%)$ were physicians, 11 $(12.36 \%)$ were healthcare administrators while19 $(21.35 \%)$ were non-physician healthcare provider. About 30.77\% communityparticipants had heard about medical devices recycling compared to $57.30 \%$ participants from healthcare sector (Fig. 1).

Only $1.71 \%$ of healthcare professionals were found to have CIEDsimplanted in them compared to $14.61 \%$ participants from community andfuneral homes. Totally $41.88 \%$ of community participants group hadfamily members or friends with CIEDs compared to $80.90 \%$ of healthprofessionals. 


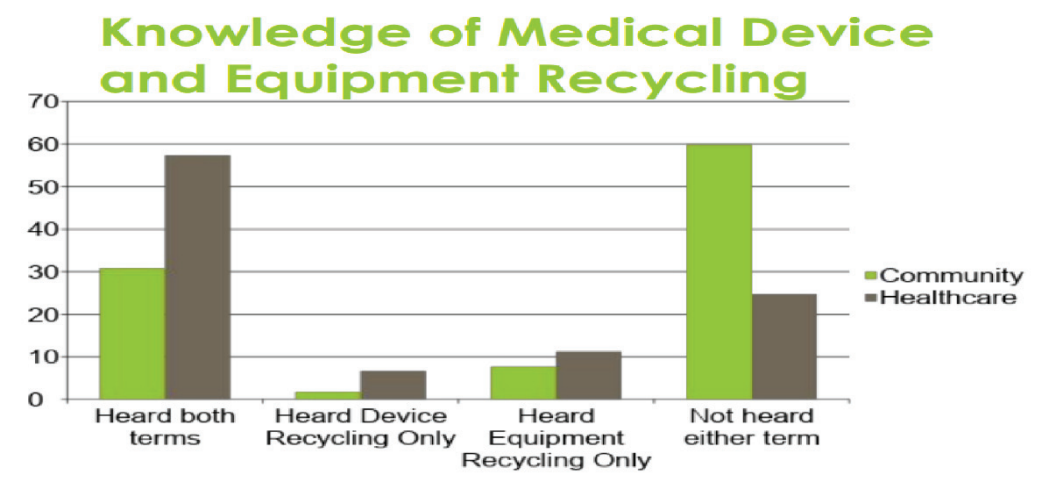

Figure 1. Bar diagram showing comparative responses about pre-existing knowledgeabout medical device and/or medical devices recycling among respondersfrom community (including funeral homes) versus healthcare personnel.

There were $51.69 \%$ of medical professionals said theywere aware that CIEDs could potentially be removed after death anddonated to other people compared to $20.51 \%$ of non-medical professionals; and $88.64 \%$ of medical professionals were aware that there are peoplein the world who die because they cannot afford CIEDs while $73.50 \%$ of community participants were also found to be aware of this fact.Higher percentages of healthcare professionals were found to be willingto personally consider a decision about medical device donation comparedto community participants (Fig. 2a,b).

There were $78.63 \%$ of community participants who thought that participationin medical device donation adds meaning to one's life while $67.42 \%$ of medical professionals agreed that device donation adds meaningto their organization's core mission. About $13.48 \%$ of healthcareprofessionals believed that hospital or healthcare organizations thatthey were associated with would be willing to potentially implementa program of postmortem CIED donation and $20.22 \%$ only believed thattheir values would potentially disallow them to personally participatein CIED donations. Only $2.59 \%$ of non-medical participants in the surveybelieved that their religious or any other beliefs would disallowthem to participate in device donation. The most common concern aboutCIED donation amongst both the groups was "risk of infection"followed by "potential lawsuits due to device malfunctions."All 89 participants amongst medical professional responded to thisquestion but only 115 participants amongst community/funeral homesresponded to this question. All the responses to this question aresummarized in Table 2.

Twenty-six healthcare professionals $(29.55 \%)$ estimated that around $60-80 \%$ of medical device and devices are trashed while one did notchoose to answer this question. Thirty-four non-medical professionalparticipants in the survey $(29.31 \%)$ estimated that around 60-80\% amedical device and devices are trashed. Most healthcare professional(53\%) estimated that around $2-10 \%$ of devices are given to other peoplein need while most community/funeral homes participants (50.44\%) estimatedthat $10-50 \%$ of these devices are given to people who were actuallyin need. A totally of $83(93.26 \%)$ of healthcare professionals preferredthe medical devices to be donated to people in need within the communityand similar results were obtained amongst community participants as 113 out of 117 total responders to this question $(96.58 \%)$ opted forlocal donation (Fig. 3). Notably,90.91\% of healthcare professional and 97.44 percentages of total community/funeralhomes participants were found to be in favor of a sound mechanismto deliver CIEDs to poor and needy people overseas and were willingto spread the word and/or participate in the same. It was also noticedthat people that their family/friends with implantable cardiac de-

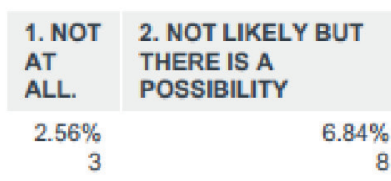

a

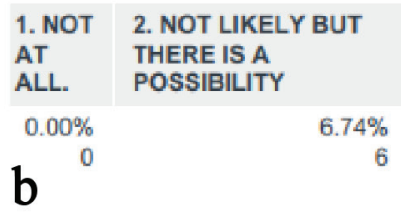

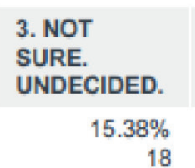
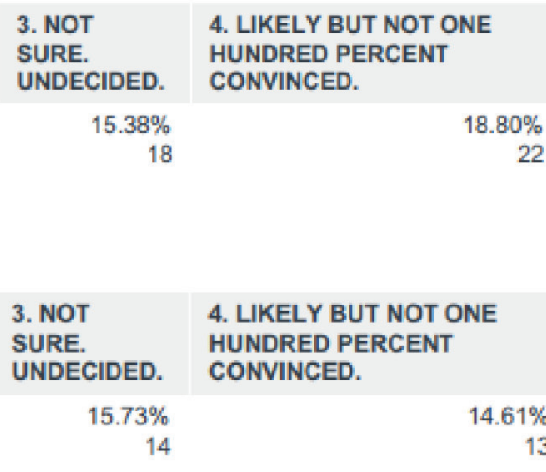

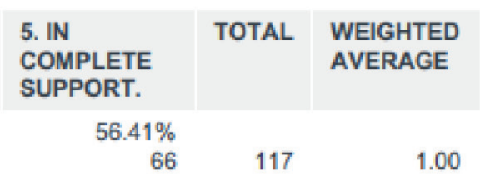

22

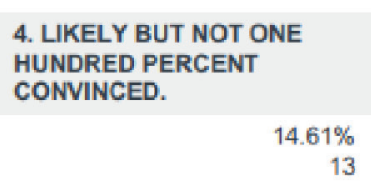

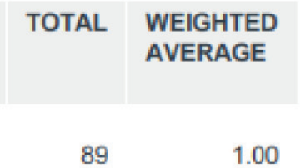

Figure 2. (a) Response among community participants about how likely theyare to personally consider/influence a decision about medical devicedonation (on a scale of 1 - 5). (b) Response among healthcare professionals(lower table) about how likely they are to personally consider/influencea decision about medical device donation (on a scale of 1 - 5). 
Table 2. Concerns About CIED Donation

\begin{tabular}{lll}
\hline Answer choices & $\begin{array}{l}\text { Responses by healthcare } \\
\text { professionals }\end{array}$ & $\begin{array}{l}\text { Responses by community } \\
\text { members }\end{array}$ \\
\hline I am concerned about disfiguring one'sbody after death & $4(4.49 \%)$ & $8(6.96 \%)$ \\
\hline I am concerned about risk of infection & $40(44.94 \%)$ & $57(49.57 \%)$ \\
I think this may be illegal & $9(10.11 \%)$ & $3(2.61 \%)$ \\
I think there may be potential threatof & $39(43.82 \%)$ & $25(21.74 \%)$ \\
lawsuits in device malfunctions & & 0 \\
I have no concerns & $26(29.21 \%)$ & $22(19.13 \%)$ \\
\hline Multiple above concerns & $11(12.36 \%)$ & \\
\hline
\end{tabular}

vicesare more likely to be positive in that support for medical recycling:93.88\% compared to those people who did not have a family member orfriends with such devices $(79.141 \%)(\mathrm{P}<$ 0.05 ). About $9.09 \%$ ofhealthcare administrators were willing to implement the medical devicerecycling in their respective institutions despite their appreciationabout the idea per se.

\section{Discussion}

Reutilization of CIEDs is a very feasible option and a great sourceof healthcare resource for underprivileged communities. Postmortemextraction of CIEDs is a prime source of explanted devices for reutilization[1]. In the United States, around 225,000 PPMs are implanted every year [5] and these devices have average longevity of $11.2 \pm 2.6$ years [7]. Ithas been estimated that around $85 \%$ of deceased with CIEDS are buriedwithout getting these devices removed [3]. According to a study in 2012, funeral homes in Michiganwere able to collect 3,176 devices, out of which $21 \%$ had good batterylife $[8,9]$. Thus, there are feasible options to obtain CIEDsfor the purpose of recycling and utilization. In spite of this feasibility,awareness regarding the benefits of recycled CIEDs is low in our communityas evident in our sample study. Even amongst people who know aboutreutilization of CIEDs, there exist a disparity between belief andimplementation. As seen in our study as well, over $90 \%$ of participantswere found to be personally supporting

\section{Overall Attitudes}

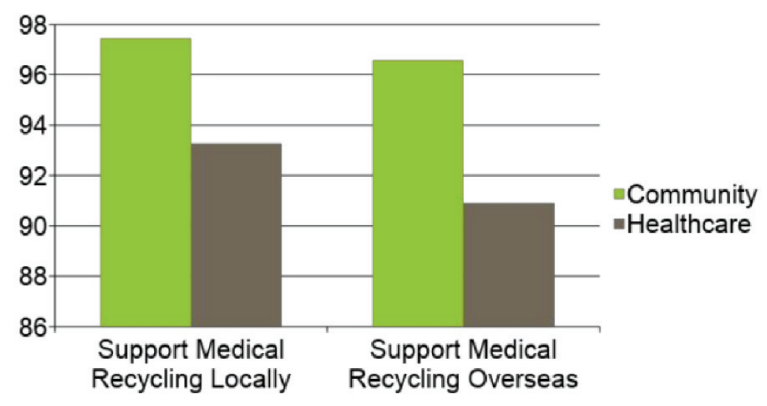

Figure 3. Both healthcare and community level participants in the surveyheavily preferred the donation of medical devices to local peopleover sending them to foreign countries. medical recycling and around $55 \%$ think that medical recycling is in line with their organization'score mission but only $9 \%$ out of these want to definitely support implementationin their hospitals. The main concerns among healthcare professionalsand community members regarding implementation of medical recyclingof CIEDs are infections and malfunctions related to the devices. Severalstudies have shown that reutilization of CIEDs do not actually increasethe risk of infection or mortality in comparison to newer surgicalimplantation of device. As per a meta-analysis regarding reuse ofPPMs performed on a pooled data of 2,270 subjects, there was no significantdifference in infection rate between recycled PPMs and new ones [9]. The concern for legal lawsuitdue to malpractice associated with CIEDs is higher among healthcareprofessional. To increase the popularity of medical recycling andnegate the fear of increased infection risk and malpractice suits, there is a need for standardized disinfection process for recycleddevices that is approved and accepted by a governing legal body. Therehas to be a formal process to re-certify these devices and devices. The United States Food and Drug Administration (US-FDA) considersCIEDs as single-use devices and thus views it as an objectionablepractice to reutilize them [10]. Since there are no federal laws to address the ownership of CIEDsafter a patient's demise, there is no definite individual orcompany who can solely lay claim to explanted CIEDs [11]. Thus, an advanced directiveoutlining the patient wishes about reutilization of implanted cardiacdevices has been suggested by some authors to help guide funeral homesin the process of retrieving CIED for the purpose of donation. Effortshave to be made to convince people that there is nothing illegal aboutmedical recycling and subsequent reutilization of devices like CIEDs.Awareness regarding these issues can be made more rampant with helpof larger group of volunteers who can spread the masses effectively.Electronic media, websites dedicated to medical device recycling andeducation tools like brochures and pamphlets can be utilized to spreadthe message. The concern about supporting medical recycling overseascan be minimized by standard device procurement, re-implantation andfollow-up process.

\section{Conclusions}

Reutilization of medical devices like CIEDs is a noble cause whichhas widespread support of both community people and 
healthcare personnel.It is very feasible to obtain CIEDs from a deceased person and thiscan improve the quality of life of many patients. However, there remainsome concerns, mainly infection and legal concerns among healthcareadministrators which we should address before implementing this ona large scale.

\section{Conflict of Interest}

The authors declare no conflict of interest.

\section{References}

1. Runge MW, Baman TS, Davis S, Weatherwax K, Goldman E, EagleKA, Crawford TC. Pacemaker recycling: A notion whose time has come. World J Cardiol. 2017;9(4):296-303.

2. Gakenheimer L, Romero J, Baman TS, Montgomery D, Smith CA,Oral H, Eagle KA, et al. Cardiac implantable electronic device reutilization:battery life of explanted devices at a tertiary care center. PacingClin Electrophysiol. 2014;37(5):569-575.

3. Badin A, Baman TS, Eagle KA, Crawford TC. Pacemaker reutilizationfor those in underserved nations: examining preliminary data and futureprospects. Interventional Cardiology. 2013;5:695-702.

4. Lamas GA, Orav EJ, Stambler BS, Ellenbogen KA, Sgarbossa EB,Huang SK, Marinchak RA, et al. Quality of life and clinical outcomesin elderly patients treated with ventricular pacing as compared withdualchamber pacing. Pacemaker Selection in the Elderly
Investigators.N Engl J Med. 1998;338(16):1097-1104.

5. Mond HG, Irwin M, Ector H, Proclemer A. The world survey ofcardiac pacing and cardioverter-defibrillators: calendar year 2005an International Cardiac Pacing and Electrophysiology Society (ICPES)project. Pacing Clin Electrophysiol. 2008;31(9):1202-1212.

6. Patel JD, Schmier J, Lau E. Healthcare costs for Cardiac Implantableelectronic device (CIED) revision procedures from 2004-2012. Circulation:Cardiovascular Quality and Outcomes.2015;8:A326.

7. Benkemoun H, Sacrez J, Lagrange P, Amiel A, Prakash A, HimmrichE, Aime E, et al. Optimizing pacemaker longevity with pacing modeand settings programming: results from a pacemaker multicenter registry.Pacing Clin Electrophysiol. 2012;35(4):403-408.

8. Baman TS, Crawford T, Sovitch P, Meier P, Sovitch N, GakenheimerL, Kirkpatrick J, et al. Feasibility of postmortem device acquisitionfor potential reuse in underserved nations. Heart Rhythm. 2012;9(2):211-214.

9. Baman TS, Meier P, Romero J, Gakenheimer L, Kirkpatrick JN,Sovitch P, Oral H, et al. Safety of pacemaker reuse: a meta-analysiswith implications for underserved nations. Circ Arrhythm Electrophysiol.2011;4(3):318-323.

10. US FDA Compliance Manuals. CPG Sec 310.100 Pacemaker Reuse(CPG) 7124.12). [accessed 2015 Dec 12] Available from: http://www.fda.gov/ICECI/ComplianceManuals/CompliancePolicyGuidanceManual/ ucm073891.htm.

11. Kirkpatrick JN, Papini C, Baman TS, Kota K, Eagle KA, VerdinoRJ, Caplan AL. Reuse of pacemakers and defibrillators in developingcountries: logistical, legal, and ethical barriers and solutions.Heart Rhythm. 2010;7(11):16231627. 